\title{
MERCADO FUTURO E FÍSICO DE SLCC: CONHECIMENTO E USO NO AGRONEGÓCIO CITRÍCOLA DO BRASIL ${ }^{1}$
}

\author{
MARIAFLÁVIADE FIGUEIREDOTAVARES ${ }^{2}$
}

RESUMO-O presente estudo teve como objetivo analisar por que as indústrias processadoras de suco concentrado e congelado de laranja não estão negociando na New York Board of Trade como hedger, considerando que o risco de preços é alto neste setor, e preferindo utilizar o preço de Roterdã como base para as suas negociações.Os mercados derivativos de commodities agrícolas são utilizados na administração do risco de preços, e a maioria dos contratos negociados em bolsas de mercadorias no mundo inteiro têm tido sucesso, mas, no caso do suco de laranja concentrado e congelado, negociado na NYBOT (atual IntercontinentalExchange (NYSE:ICE)), o volume de negociação de contratos é baixo em comparação com outras commodities.Mas os custos de transação relacionados ao mercado futuro de SLCC, aliados com a concentração das empresas brasileiras processadoras de suco concentrado de laranja, acabaram induzindo um modo alternativo de governança neste setor: o mercado a termo.

Termos para indexação: Sistema Agroindustrial Citrícola, Mercados Derivativos, Economia dos Custos de Transação.

\section{FUTURE AND PHYSICAL MARKET OF FCOJ: KNOWLEDGE AND USE BY CITRUS AGRIBUSINESS OF BRAZIL}

ABSTRACT- The objective of the present study was to analyze why Frozen Concentrated Orange Juice Industries do not trade in the New York Board of Trade as hedger, considering that the risk of prices is high in this sector, and they prefer to use the price of Rotterdam as base for negotiation. The derivative markets for agricultural commodities are used in the administration of price risk and the majority of contracts negotiated in Stock Markets of Commodities in the entire world has had success, but in the case of the frozen concentrated orange juice negotiated on the NYBOT (actual IntercontinentalExchange (NYSE:ICE), the volume of contract negotiation is low when compared to others commodities. However, the costs of transaction related to the future market of FCOJ, together with the concentration of Brazilian Industries that produce FCOJ, have induced an alternative way of management in this sector: the forward market.

Index terms: Agroindustrial Citrus System, Derivative Markets, Transaction Costs Economy.

\section{INTRODUÇÃO}

O sistema agroindustrial da laranja tem grande importância para a economia brasileira com a receita das exportações de suco de laranja concentrado e congelado (SLCC), em 2006, atingindo US $\$ 1,043$ bilhão $(972.750,41 \mathrm{t})$, cerca de $2,4 \%$ do total dos agronegócios e de 0,9\% das exportações totais do Brasil. Em 2007, as exportações brasileiras de SLCC atingiram US $\$ 1,054$ bilhão $(976.363,59$ t), sendo que a receita da indústria processadora e exportadora cresceu $47,9 \%$ em relação a 2006 . As exportações de suco de laranja do Estado de São Paulo (maior produtor brasileiro) representaram $95,8 \%$ do total nacional, em 2005 corresponderam a 9\% das exportações do agronegócio paulista e 2,8\% das exportações totais do Estado (Associtrus,2006). As exportações de SLCC sustentam toda uma infra-estrutura de produção de matéria-prima e de processamento do produto, com efeitos diretos e indiretos na geração de empregos, na receita pública e nas demais atividades econômicas do Estado de São Paulo, o que faz com que a agroindústria citrícola paulista tenha grande papel social no País. O mercado de suco de laranja é caracterizado como sendo um oligopsônio, onde, de um lado, poucas empresas são responsáveis pela compra da produção de laranja e, do outro, milhares de produtores vendem o produto. De acordo com Margarido (1998), as indústrias processadoras de SLCC do Estado de São Paulo possuem elevado grau de concentração econômica, que acaba garantindolhes algum poder capaz de provocar importantes transformações sobre a estrutura de mercado. Segundo Maia (1996), as barreiras à entrada de novas firmas são impostas, na maioria das vezes, pelas grandes empresas presentes no mercado e que possuem grandes vantagens sobre as concorrentes. Na Europa, existe um grande número de empresas engarrafadoras de suco e, a partir dos anos 90, vem aumentando a concentração entre as empresas processadoras, engarrafadoras, varejistas e atacadistas, atuantes no mercado de suco de laranja. Nos Estados Unidos, a concentração é maior, sendo que existem três grandes empresas com 60\% do mercado: Pepsi (Tropicana), Coca-Cola (Minute Maid) e Florida's Natural. Considerando-se também a participação das marcas próprias dos supermercados com sucos processados por elas, as três maiores empresas do mercado controlariam aproximadamente $80 \%$ da participação total (Binkley et al., 2002). Usualmente, a formação dos preços do SLCC no mercado mundial

${ }^{1}$ (Trabalho 225-07). - Recebido em: 25-09-2007. Aceito para publicação em: 04-11-2008.

${ }^{2}$ Economista, Dra em Agronegócio, coordenadora adjunta e pesquisadora do Nùcleo de Estudos do Agronegócio-ESPM. Endereço da instituição: Rua Joaquim Távora,1240,2 andar, Vila Mariana, São Paulo-SP, CEP-04015-013.E-mail:mtavares@espm.br. 
tem como referência a Bolsa em New York; porém, atualmente, o balizamento de preços do suco brasileiro está sendo deslocado para Roterdã, um importante porto na Europa (Holanda), um mercado físico onde não ocorrem transações futuras. Os mercados derivativos representam uma alternativa para administrar a flutuação dos preços das commodities agrícolas, possibilitando também a seus participantes buscar um ganho financeiro em seus diversos tipos de operações. De acordo com Jorion (1998, p.123), um contrato de derivativos pode ser definido como "um contrato privado que deriva a maior parte de seu valor de algum ativo, taxa referencial ou índice-objeto como uma ação, um título, uma moeda ou uma commodity".Os mercados derivativos vêm ganhando importância e dando novos contornos ao mercado de commodities agrícolas e gerando efeitos de curto a longo prazos no setor agroindustrial.

RISCOS DO SETOR: As empresas processadoras de SLCC e os produtores de laranja estão expostos a diversos riscos, como o risco de produção e o de preço. Os engarrafadores de suco e os traders que negociam no mercado internacional correm os riscos principalmente de não receberem a mercadoria, devido a problemas com a produção do suco. Em 1966, a New York Board of Trade (NYBOT) passou a negociar contratos futuros de SLCC, que foi o primeiro produto agrícola totalmente processado a ser negociado com sucesso em Bolsas de Mercadorias. O principal objetivo da introdução desses contratos pela NYBOT era o de dar orientação à indústria de citros na Flórida. Em 1985, são introduzidos os contratos de opção sobre contratos futuros de SLCC (NYBOT,2005). No final de 2007, a NYBOT foi vendida para a IntercontinentalExchange (NYSE: ICE),que manteve os contratos de suco de SLCC; nestes, são especificadas a unidade de negociação de 15.000 libras-peso de sólidos solúveis, cuja cotação é em centavos de dólar e centésimos de um centavo, o objeto de negociação é tipo $\mathrm{A}^{1}$, com menos de 62.5 graus Brix e os produtos são originados do Brasil e/ou Flórida. A entrega física de barris de $200 \mathrm{~kg}$ ou tanques ocorre em armazéns licenciados pela Bolsa na Flórida, New Jersey, Dalaware e Califórnia. Em outubro de 2006, a NYBOT introduziu o contrato futuro de $\mathrm{NFC}^{2}$ (Not-From Concentrate, ou seja suco de laranja não-concentrado), pois o volume de negociação do contrato de SLCC teve uma redução devido a diversos fatores, como a substituição do consumo de SLCC por NFC, um produto cujo consumo cresce a taxas mundiais de $35 \%$. No contrato de NFC, a unidade de negociação é de 12.000 libras-peso de sólidos solúveis, a cotação é em centavos de dólar e centésimos de um centavo, o objeto de negociação é Grau A com 11,5 a 12,5 graus Brix e os produtos são originados somente da Flórida. Segundo Hart (2004), desde o início dos anos 90, vem aumentando o consumo de NFC e diminuindo o consumo de SLCC nos Estados Unidos; em 1998, a venda de NFC em supermercados representou $51 \%$ das vendas de sucos nesse país. Muitos fatores podem afetar a oferta de suco de laranja: estoques de suco, geadas na
Flórida, doenças e secas no Brasil, e esta sensibilidade combinada com um mercado global competitivo de sucos e bebidas tornam o preço do SLCC volátil. O preço do NFC também é influenciado pelos fundamentos do mercado, mas tende a ser menos volátil que o preço do SLCC. Mas, além dos fundamentos do mercado, é necessário acompanhar o movimento dos fundos de investimentos, que estão investindo bilhões de dólares em contratos de petróleo, cobre e commodities agrícolas, como soja, trigo e suco de laranja. Os fundos atuam como grandes especuladores e migraram suas aplicações para as commodities, buscando alta rentabilidade e proteção contra a crise do mercado de crédito nos Estados Unidos, provocando, no curto prazo, oscilações de preços consideráveis nesses mercados. Pyndick (2001) considera que a volatilidade dos mercados leva produtores e consumidores de commodities a fazerem hedge para poderem administrar o risco do mercado; os instrumentos negociados nesse mercado incluem os contratos futuros e de opções. $\mathrm{O}$ conceito de hedge está associado à contratação de operações no mercado financeiro que diminuam o impacto de fatores imprevisíveis e, para utilizar esse instrumento de proteção, é preciso inicialmente identificar e, de certa forma, quantificar os fatores de riscos e, a partir dessa ação, decidir quanto e o quê proteger. Os hedgers são os agentes econômicos que atuam no mercado futuro e que possuem interesse comercial direto pelo produto, como os produtores, exportadores, processadores, atacadistas e varejistas.

MERCADO FÍSICO DE ROTERDÃ: O Porto de Roterdã é utilizado para distribuir o SLCC (60\% do mercado europeu de suco) e outras commodities, como cereais, fumo, café e carne para a Europa (25 milhões de toneladas de alimentos), sendo que sua participação de mercado (40,7\%) é maior em comparação com os outros portos- Antuérpia (14,4\%), Hamburgo $(9,0 \%)$ e Zeebrugge (4,4\%), (Saulnier,2004). Existe uma elevada correlação entre os preços vigentes no Brasil, em New York e os preços em Roterdã, que estão sendo usados como base pela indústria processadora em seus contratos de venda de SLCC para as engarrafadoras de sucos (Gráfico1). Essa alta correlação mostra que os preços praticados em Roterdã são atrelados aos preços de fechamento na Bolsa em New York (cujos preços atuam como sinalizadores do mercado). De acordo com Lara (2005), contratos plurianuais estipulam preços definidos e cláusulas de proteção a seu favor e, para poder honrar esses contratos, a indústria forçosamente tem de carregar estoques para manter seu risco sob controle e também para garantir o atendimento da demanda.Os contratos realizados entre as empresas processadoras e engarrafadoras são contratos a termo, onde ocorre a negociação de uma quantidade específica de um bem, por um preço específico, para ser liquidado em uma data futura determinada. Há flexibilidade na negociação das condições de preço, prazo, garantia e formas de liquidação nesses contratos.

${ }^{1}$ O Departamento de Agricultura dos Estados Unidos (USDA) determinou que, para o SLCC ter grau A, ele deve atender aos seguintes requisitos: cor mínimo 36 pontos; defeitos-mínimo 18 pontos; sabor- 36 pontos; e atingir o total mínimo de 90 pontos.

${ }^{2}$ Estes contratos ainda não tiveram sucesso, segundo os dados divulgados pela Intercontinental Exchange (NYSE: ICE); em 2007,foram negociados apenas 154 contratos 


\section{MATERIAL E MÉTODOS}

${ }_{3} \mathrm{O}$ presente artigo foi baseado na tese de doutorado da autora ${ }^{3}$, que pode ser classificada como uma pesquisa qualitativa, e a metodologia utilizada no trabalho foi baseada em dados primários e secundários, sendo que os dados primários foram obtidos por meio de entrevistas semi-estruturadas com pessoas selecionadas intencionalmente entre produtores de laranja, executivos das indústrias processadoras de suco de laranja, instituições de pesquisa e traders. Os dados secundários foram obtidos a partir de um levantamento bibliográfico realizado em bibliotecas, sites da Internet e banco de dados, e as principais fontes utilizadas foram:ABECITRUS, ASSOCITRUS, Florida Department of Citrus, USDA, FOODNEWS, MAPA, SECEX, NYBOT, IEA, BM\&F, USP, UNICAMP. Para se obterem os dados primários, foram realizadas entrevistas em profundidade, conduzidas por um roteiro de perguntas abertas sobre os seguintes temas: mercado internacional de SLCC; mercado físico de laranja e de suco de laranja; contratos a termo e contratos futuros, e também sobre o futuro da citricultura brasileira. Mas o presente artigo apenas apresentará os resultados relacionados ao mercado a termo e ao mercado futuro de SLCC. Na etapa inicial da pesquisa, foi utilizado um estudo-piloto com cinco executivos de indústrias do setor citrícola, cinco profissionais que trabalham com mercado futuro de commodities agrícolas e dois pesquisadores de instituições de pesquisas que trabalham com a citricultura nos Estados de São Paulo e Rio Grande do Sul, com o objetivo de avaliar a importância do tema a ser estudado.Após essa etapa, foram coletados os dados secundários e realizada extensa revisão bibliográfica, além de visitas informais a duas empresas do setor e também ao terminal de embarque de suco de uma grande empresa processadora de suco concentrado de laranja, localizado no porto de SantosSP.Foram selecionados vinte produtores das regiões paulistas de Campinas, Araraquara, Catanduva, Matão, São José do Rio Preto, Itapetininga e também dois produtores da região de Paranavaí (PR) e um (1) assessor técnico de uma cooperativa de produtores em Chapecó (SC).Os produtores do Estado de São Paulo foram escolhidos por meio do cadastro de uma empresa privada do setor, por possuírem em seu perfil algumas características que os caracterizavam como prováveis hedgers da NYBOT: são médios (segundo o relatório apresentado por Paulillo (2005) ), (com cerca de 400.000 pés de laranja) e grandes produtores (com cerca de 900.000 pés de laranja), possuem atividades com fins comerciais e formação de nível superior, o que facilita o acesso às informações do mercado futuro de SLCC. Os pequenos produtores (com cerca de 16.000 árvores) do Estado do Paraná e Santa Catarina foram entrevistados com o objetivo de conhecer o mercado de sucos orgânicos. Ao entrevistar os produtores, pretendia-se buscar informações sobre as transações no mercado físico entre produtores e empresas processadoras, o seu conhecimento no mercado internacional de suco de laranja e também verificar o grau de conhecimento em relação ao funcionamento do mercado futuro e de opções, e se eles operam neste mercado. O objetivo das entrevistas com os traders foi o de conhecer mais profundamente as transações que ocorrem no mercado internacional entre empresas processadoras de suco de laranja e os seus clientes. Foram entrevistados, por meio de entrevistas pessoais e por telefone, nove traders (sendo que cinco já tinham sido entrevistados na etapa inicial) de empresas comerciais do Brasil e dos Estados Unidos, que negociam suco de laranja no mercado internacional, sendo que as entrevistas pessoais foram realizadas nas cidades de São Paulo e Bragança Paulista (SP). Foram realizadas entrevistas pessoais e por mensagem eletrônica com três pesquisadores(sendo que dois pesquisadores são os mesmos da etapa inicial da pesquisa) do setor citrícola pertencentes a instituições públicas, localizadas no Estado de São Paulo e no Estado do Rio Grande do Sul, com o objetivo de conhecer o setor e também sobre a existência de trabalhos de pesquisa a respeito do mercado futuro de suco de laranja concentrado e congelado. Foram realizadas entrevistas com sete executivos (sendo que cinco já haviam sido entrevistados na etapa inicial) das indústrias processadoras, com o objetivo de conhecer as transações entre produtores de laranja e empresas processadoras de suco, conhecer as transações dessas empresas no mercado internacional, mais especificamente em Roterdã, e também se ocorrem transações com a NYBOT.

\section{RESULTADOS E DISCUSSÃO}

Contratos a Termo: O tipo de contrato que está sendo feito pelas engarrafadoras e empresas processadoras de SLCC pode ser definido como um contrato a termo, pois ocorrerá entrega física, existe uma especificação do produto, da data e do local de entrega e um preço preestabelecido pelas partes. Por ser um contrato a termo, existe um risco maior na transação devido à oscilação dos preços e também ao possível oportunismo por uma das partes, o que não ocorre no mercado futuro, onde existe a Câmara de Compensação que garante o cumprimento dos contratos. De acordo com Black (1986), a contratação a termo vem sendo usada para níveis mais sofisticados de alguns mercados, mas os participantes correm riscos de inadimplência da contraparte do contrato, sendo necessárias salvaguardas contratuais e garantias. Baseando-se em Williamson (1996), que considera que a Economia dos Custos de Transação (ECT) se propõe a explicar as estruturas de governança criadas para reduzir os riscos envolvidos em uma transação, observa-se que o mercado a termo está sendo utilizado como governança nas transações contratuais entre empresas processadoras de suco de laranja e engarrafadoras de suco na Europa. No contrato a termo entre engarrafadoras e empresas processadoras, as partes procuram proteger-se do risco, tentando ajustar o preço conforme os acontecimentos do mercado, e, na maior parte das vezes (segundo informações obtidas nas entrevistas), este pode não ser o mesmo em todo o contrato, ao ter a duração de vários anos.

${ }^{3}$ O Mercado Futuro de Suco de Laranja Concentrado e Congelado: um Enfoque Analítico.Tese de doutorado em Agronegócios realizada no CEPAN/ UFRGS e defendida em abril de 2006. 
Ao contrário dos contratos futuros, naqueles a termo, as transações são baseadas na confiança de que o produto será entregue conforme o contratado, na data e nas especificações preestabelecidas, pois as empresas têm um nome a zelar e precisam garantir a sua idoneidade no mercado. Os contratos estabelecem cláusulas para evitar o oportunismo, mas, mesmo assim, se esses contratos fossem negociados e registrados em Bolsas, eles teriam uma proteção maior. As empresas processadoras de suco de laranja informaram, nas entrevistas, que não operavam na NYBOT, pois preferiam utilizar apenas os preços dessa bolsa como sinalizador de suas negociações em Roterdã. Entre os motivos citados nas entrevistas, estariam os altos custos relacionados às operações na Bolsa e também porque o mercado a termo permite negociações mais flexíveis em relação a preço, qualidade do suco, local de entrega, etc.A frequiência das transações entre indústria processadora e engarrafadora de suco permite que sejam reduzidos os custos de transação relacionados à elaboração de contratos, conhecimento do mercado, relacionamento pós-venda, o que leva também à diminuição do oportunismo entre as partes. Segundo Oliveira (2003), as maiores dificuldades das Bolsas relacionam-se em como conseguir interessados para negociar os contratos com freqüência e volume, garantindo a liquidez destes. De acordo com Brorsen \& Fofana (2001), os contratos futuros podem fracassar (ou terem problemas) quando o mercado físico de uma commodity se torna mais concentrado, e isto se aplica no mercado de suco de laranja, onde as indústrias processadoras de SLCC do Estado de São Paulo possuem um elevado grau de concentração econômica. Houve evolução do volume negociado de contratos de SLCC na NYBOT, sendo que, em 2003, foram negociados 652.750 contratos, em 2005 o número de contratos negociados representou cerca de 900.000 (1.031 mil toneladas de suco a $66^{\circ}$ brix). Até junho de 2008 , foram negociados 331.562 contratos futuros de SLCC. Entre os motivos, que pode ser constatado nas entrevistas, é o desinteresse dos produtores e empresas processadoras brasileiras em operar nessa bolsa. Atualmente, os maiores participantes desse mercado são especuladores como fundos de hedge e bancos, e também algumas empresas que operam no mercado futuro de outras commodities (Commitments of Traders Report, 2008). Como já foi discutido anteriormente, devido ao baixo volume de negociação do SLCC, a NYBOT resolveu lançar o contrato futuro de NFC, como uma opção para movimentar o mercado de suco de laranja. Quando o mercado futuro de uma commodity não tem muito sucesso, as bolsas procuram adaptálo à realidade do mercado, e essa estratégia foi utilizada em fevereiro de 2004, quando o novo contrato FCOJ-A substituiu o contrato FCOJ-1 ${ }^{4}$, que foi o primeiro contrato de suco de laranja negociado na NYBOT. Como estratégia para maior movimentação no mercado futuro de suco de laranja e obter mais sucesso, a Bolsa procurou adaptar seus contratos à realidade do mercado e também lançar novos contratos a partir de fevereiro de 2004. Assim, foram estabelecidas novas especificações, a saber: a) (em fevereiro de 2004) o novo contrato FCOJ-A substituiu o contrato FCOJ-1, que foi o primeiro contrato de suco de laranja negociado na NYBOT; b)os contratos passaram a ser denominados FCOJ-A e FCOJ-B, cuja principal diferença está na origem do suco que deve ser da Flórida ou do Brasil; c) em outubro de 2006, foi lançado o contrato futuro de NFC. Em março de 2008, a Intercontinental Exchange (NYSE:ICE) resolveu mudar novamente o contrato de SLCC com o objetivo de aumentar a liquidez desse mercado, o novo contrato substituiu os 2 anteriores e passou a ser mundial, sendo que a origem do suco será do Brasil, Estados Unidos, Costa Rica e México. As outras especificações, como, por exemplo, mês e horário de negociação, tamanho do contrato, permanecem as mesmas. Nos contratos a termo entre as indústrias processadoras e engarrafadoras, os preços são determinados entre as partes, e desse modo são menos transparentes, formados no mercado. A concentração existente no segmento do processamento do suco de laranja reflete-se nos preços da commodity que muitas vezes são alterados com o aumento ou diminuição dos estoques, motivados por decisões estratégicas das empresas.

Contratos Futuros: Os traders acompanham o mercado futuro para ver o comportamento do mercado físico, pois fazem negociações de compra e venda da commodity e necessitam que ocorra a entrega física da commodity, o que geralmente não ocorre no mercado futuro, onde são negociados contratos. Alguns traders operam com outras commodities como especuladores e realizam operações de arbitragem em outras Bolsas de Mercadorias, como Chicago Board of Trade (CBOT) e NYSE Euronext. Outra questão relacionada ao mercado futuro de SLCC refere-se ao fato de que os produtores demonstraram desconhecer o mecanismo de funcionamento desse mercado, e este pode ser considerado também um custo de transação relatado por autores como Hirshleifer (1998), pois esse desconhecimento impediria a entrada desses produtores ao mercado futuro, havendo a necessidade de investirem em cursos de capacitação, o que acabaria gerando custos. Os entrevistados relataram também que o fato de a Bolsa ser localizada em outro país e a existência de poucas corretoras que operam com SLCC no Brasil, dificultam o acesso ao mercado. Esse fato também gera custos de transação, pois além de terem de submeter-se às taxas cobradas por estas poucas corretoras (que, devido à falta de concorrência, podem ser superiores, como se houvesse um número maior de corretoras operando neste mercado), e existe também a barreira do idioma.

${ }^{4}$ Observar que FCOJ (Frozen Concentrated Orange Juice) é o mesmo que SLCC (Suco de Laranja Concentrado e Congelado).

Rev. Bras. Frutic., Jaboticabal - SP, v. 30, n. 4, p. 925-930, Dezembro 2008 


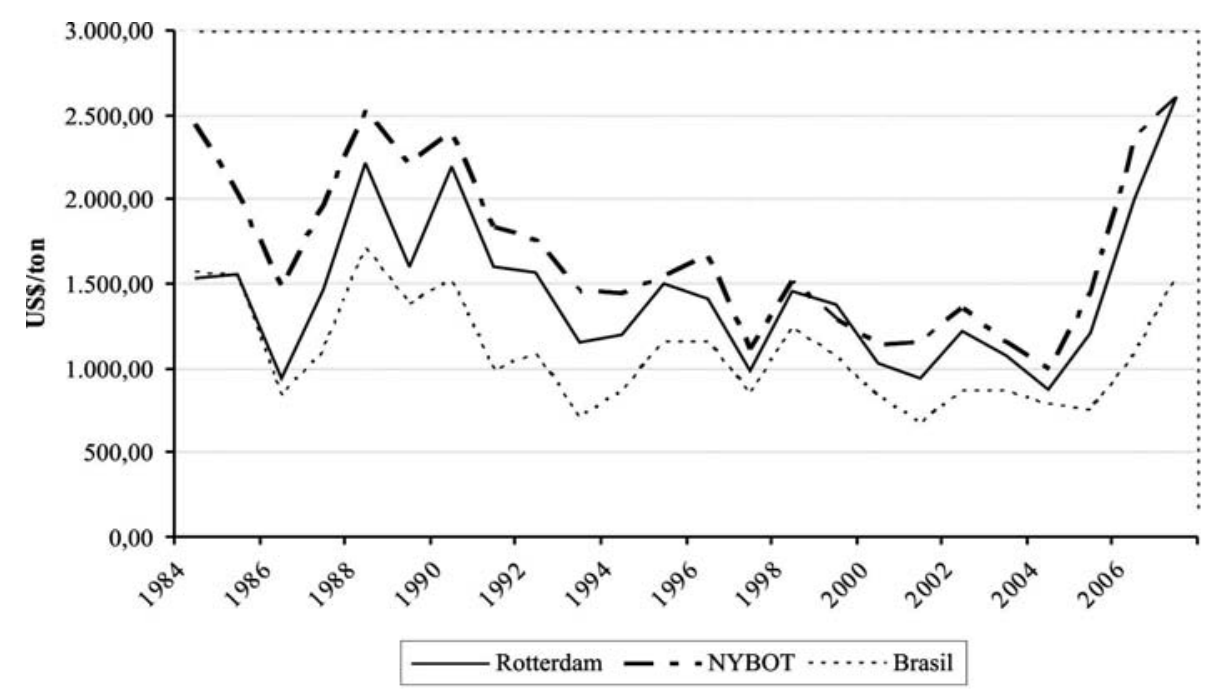

Fonte:Elaborada com dados originais de NYBOT (2007), Foodnews (2007)-Roterdã, USDA (2007), SECEX (2007).

FIGURA 1- Média Anual de SLCC:Roterdã, NYBOT e Brasil, de 1984 a 2007*.

*até maio 2007

\section{CONCLUSÃO}

Os mercados derivativos de commodities agrícolas são utilizados na administração do risco de preços, e a maioria dos contratos negociados em bolsas de mercadorias no mundo inteiro têm tido sucesso, mas no caso do SLCC, negociado na NYBOT (a Intercontinental Exchange (NYSE:ICE), o volume de negociação de contratos é baixo em comparação com outras commodities negociadas nessa Bolsa. Os mercados futuros e de opções atuam como forma de governança nos outros mercados de commodities agrícolas, pois o hedge permite a diminuição do risco da transação, e o fato de a bolsa exigir salvaguardas e garantias durante o período de vigência do contrato permite a redução dos custos de transação. Os custos de transação relacionados ao mercado futuro de SLCC (altos custos dos contratos, custos de aprendizado, custos de liquidez, etc.), aliados à concentração das empresas brasileiras processadoras de suco concentrado de laranja, acabaram induzindo um modo alternativo de governança nesse setor:o mercado a termo. Essa constatação empírica confirma a teoria encontrada na Economia dos Custos de Transação, em que o custo das transações seria o indutor dos modos alternativos de governança dentro de um arcabouço analítico institucional. Os executivos das empresas processadoras entrevistadas relataram nas entrevistas que não operam na NYBOT, apenas utilizam os preços dessa Bolsa como sinalizador de seus contratos em Roterdã, e a governança do mercado vem sendo feita por meio dos contratos a termo, ocorrendo a entrega física do produto. Nas negociações entre as empresas brasileiras e os seus clientes, é utilizado o preço negociado em contratos entre as partes, e desse modo o preço é preestabelecido, assim como a qualidade e a quantidade do suco e o local de entrega. A escolha por contratos a termo pode também ser influenciada pela demanda por produtos com especificações diferentes, e mesmo a commodity sendo padronizada, pode ser alterada conforme o pedido do comprador, como, por exemplo, uma empresa quer lançar um produto novo no mercado e pede que seja produzido um suco especial apenas com uma variedade de laranja, como a Hamlim. A utilização de contratos específicos para cada cliente só é permitida nas negociações a termo, pois nos contratos futuros essa flexibilidade não ocorre, pois a qualidade e a quantidade do produto são padronizadas. Apesar de o risco ser maior nesse tipo de negociação do que em uma Bolsa de Mercadorias (que garantiria as operações), observa-se que um dos fatores principais da escolha do contrato a termo é a obrigatoriedade de entrega da commodity e também a menor complexidade desse mercado, inclusive em relação ao pagamento de taxas, sendo que as existentes no mercado futuro acabam encarecendo os valores dos contratos.

\section{AGRADECIMENTO}

Ao Dr. Paulo Dabdab Waquil e ao apoio financeiro da CAPES e CNPQ durante o período de doutorado.

\section{REFERÊNCIAS}

ASSOCITRUS - Associação Brasileira dos Citricultores. Panorama atual da citricultura. Bebedouro, 2005. Disponível em: 〈http://www.associtrus.com.br/panorama_atual.htm>. Acesso em: 02 fev. 2006.

BINKLEY, J. et al. Consolidated Markets, Brand Competition, and Orange Juice Prices. Agricultural Information Bulletin, USDA, n. 747-06, june 2002. Disponível em: <http:// 
www.ers.usda.gov/publications/aib747/aib74706.pdf>. Acesso em: 14 jul.2005.

BLACK, D. G. Success and failure of futures contracts: theory and empirical evidence. New York, NY: Salomon Brothers Center for the Study of Financials Institutions, 1986. (Monograph Series in Finance and Economics, 1986-1)

BRASIL. Ministério do Desenvolvimento, Indústria e Comércio Ex t e ri or. Sít i o. Di s p o níve le m: < h t t p : / / www.desenvolvimento.gov.br/sitio/secex/secex/ competencia.php>. Acesso em: 26 set. 2005.

BRASIL. Ministério do Desenvolvimento, Indústria e Comércio Exterior. Sítio. Disponível em: < http:// www.aliceweb.desenvolvimento.gov.br>. Acesso em: 11 junho. 2007.

BRORSEN, W.; FOFANA, N. F. Sucess and failure of agricultural futures contracts. Journal of Agribusiness, Georgia , v.19, n.2, p.129-145, 2001

COMMITMENTS OF TRADERS REPORT-CFTC. Disponível:<http://www.cftc.gov>. Acesso em: 20 jun. 2008.

FOODNEWS. [site]. Washington, DC. Disponível em: <http:// www.foodnews.org>. Acesso em: 14 ago.2005.

HART, E. The U.S. orange juice tarif and the "Brazilian Invasion" of florida: the effect of Florida. 2004, Tesis (Master of Arts in Law and Diplomacy) - Massachusetts: The Fletcher School, 2004.

HIRSHLEIFER, D. Risk, futures pricing, and the organization of production in commodity markets. Journal of Political Economy, Chicago, v.96, n.6, p.1206-1220, 1998.

INTERCONTINENTAL EXCHANGE (NYSE:ICE). New York, 2008. Disponível em: <https://www.theice.com/marketdata/
nybotreports/getMonthAndYearToDateVolumeReport.do>. Acesso em: 23 jun. 2008.

JORION, P. Value at risk: a nova fonte de referência para o controle do risco de mercado. São Paulo: BM\&F, 1998.

LARA, O. H. Maturidade do mercado europeu limita a valorização do suco. HortifrutiBrasil, Piracicaba, 2005. p.18.

MAIA, M.L. Citricultura paulista: evolução, estrutura e acordos de preços. São Paulo: IEA, 1996.

MARGARIDO, M. A. Transmissão de preços internacionais de suco de laranja para preços ao nível de produtor de laranja no estado de são paulo. São Paulo: IEA, 1998.

NYBOT - New York Board of Trade. FCOJ. New York, 2005. Disponível em: <http:// www.nybot.com/fcoj/htm>. Acesso em: 17 dez. 2005.

OLIVEIRA, V. A. Determinantes do desempenho dos contratos futuros de commodities agropecuárias no Brasil. 2003. Dissertação (Mestrado em Economia Aplicada) -Departamento de Economia Rural, Universidade Federal de Viçosa, Viçosa- MG, 2003.

PAULILLO, L.F. Custos de negociação e entraves institucionais para o citricultor. In: SEMANA DE CITRICULTURA, 27., 2005, Cordeirópolis.

PINDYCK, R.S. Volatility and commodity price dynamics. Cambridge, MA: Massachusetts Institute of Technology, 2001. p.1-38.

SAULNIER, J.M. Rotterdam, gateway to and from europe, a busy beehive of could storage activity. Quick Frozen Foods International, Fort Lee, n.1, p.18-29, 2004.

WILLIAMSON, O.E. Transaction cost economics and organization theory. New York: The Free Press-Macmillan, 1996. 